\title{
Successfully collaborating to revamp first-year instruction The case of DePaul University
}

ibrary instruction for first-year writing programs are often the bread and butter of academic libraries. Since so many of these classes are taught each semester, year after year, librarians have little time to critically reflect on what exactly we are delivering before the next academic cycle starts. Once a partnership is cemented and a program in place, it is often easier to carry on with the existing curriculum rather than attempt to make changes. Add in the difficulty of reaching adjunct faculty who often teach the bulk of these classes, and the challenges to making positive change grow exponentially.

In 2014, a group of librarians at DePaul University set out to rethink our FirstYear Writing library instruction program. By initiating this project, our group was able to set our own timeline and take a thoughtful approach. We collaborated with faculty and other librarians, developing an iterative process through which feedback was valued. We opened up a meaningful dialogue with the First-Year Writing faculty and strengthened those relationships. From start-to-finish, the process took a year-and-a-half.

\section{Background}

For over 20 years, DePaul librarians have partnered with the First-Year Writing program to ensure undergraduate students receive foundational information literacy instruction in the required course Writing, Rhetoric, and Discourse (WRD) 104. Our long-standing WRD 104 curriculum has always consisted of two parts: a full (90 minutes) class session with a librarian, along with a librarian-graded homework assignment. Over the years the homework assignment changed from a printed workbook to an online workshop, and the number of sessions taught has increased significantly. For the past several years, a group of about ten librarians has taught more than 120 in-person WRD 104 research instruction sessions each year, and graded the corresponding 3,000-plus online workshops.

In the summer of 2014, we formed the First-Year Instruction Working Group (FYIWG) to take a holistic view of the WRD 104 library instruction program, including both the in-person and online components. FYIWG viewed this as an opportunity to collaborate with faculty and librarians to closely examine a program that had not undergone significant revisions in more than

Jessica Alverson is assistant coordinator of instruction of e-learning, email: kalverso@depaul.edu, and Jennifer Schwartz is humanities and social sciences librarian, email: jschwa17@depaul.edu, at DePaul University

() 2017 Jessica Alverson and Jennifer Schwartz 
ten years. Throughout our design process, faculty and librarians had numerous opportunities for input. Communication and feedback were gathered through surveys, workshops, and meetings.

\section{Surveying (spring 2014)}

To begin the redesign, we asked WRD 104 faculty to identify the most valuable skills or concepts taught by librarians. They responded with: identifying and searching databases, creating an appropriate search strategy, differentiating between scholarly and nonscholarly resources, and understanding the difference between searching library resources and Google. Not surprisingly, they preferred active-learning to lecturing, and they wanted more attention given to higher order thinking skills, such as evaluating information.

Next, we surveyed our instruction librarians to find out what we were actually teaching in these sessions. We also asked librarians to identify concepts or skills they felt should be emphasized in our WRD 104 curriculum. From survey results, we found variation between what different librarians were teaching in the session, as well as a disconnect between what they would like to teach and what they were actually able to teach. We also found that we weren't properly leveraging the online workshop's content within the class structure, often duplicating the material found online again in-person. When we asked librarians what concepts or skills should be emphasized, they focused on many of the same topics as the faculty, highlighting evaluating information; topic development and identifying keywords; understanding databases; and locating subject-specific databases.

\section{Analyzing (spring and summer 2014)}

After gathering feedback, FYIWG began the instructional design process. Using Char Booth's USER method ${ }^{1}$ as a framework, we analyzed the existing curriculum and identified learning goals. Working through this process, we were able to step out of our roles as experts and delineate all of the things a student had to know in order to accomplish a task. Not surprisingly, we realized that librarians were trying to cover too much material in one session, not relying on the content of the online workshop. And, getting stuck in the task-related details, librarians weren't able to devote time to larger concepts. If we wanted students to retain what they learned, we needed to identify and target only the essentials. Students would also need time to practice applying these new skills to their own assignments while in the classroom, with the librarian around for advice and assistance.

While we would still need to teach some of the "where to click," it would not be the focus. We would be more purposeful about offloading some content to activities outside of the classroom. These insights directly corresponded to the suggestions from the faculty and librarians.

\section{Workshopping (summer 2014)}

We shared the results of the group's preliminary work with our team of instruction librarians and asked them to storyboard their ideal library instruction session. The group came up with a working curriculum that relied on two main assumptions. First, we wanted to make sure that students had topics before arriving in person, so that they were focused and ready to participate. Second, we needed to consistently make time for hands-on, active learning exercises during the in-person class. Librarians would consistently teach the same curriculum, but be given the option to customize the approach they used in teaching the concepts. We divided the class time into four parts, to be organized by the librarian however they liked: topic development, evaluating information (including differentiating between scholarly and nonscholarly sources), demonstrating database selection and searching, and hands-on time.

\section{Piloting (winter and spring 2015)}

We were ready to pilot the new curriculum 
in winter 2015 using a truly flipped model. In the past, some classes had completed our online workshop as homework prior to the session and others afterwards. This made it difficult to effectively plan for an instruction session. The new model would rely on pre-session homework, ensuring that students arrived prepared to start research. Knowing that all students would come to the classroom with baselevel knowledge allowed us to implement a consistent curriculum for the in-person session, as well as help with scaffolding instruction in the upper levels. Crucially, the pre-session assignments would no longer need to be graded, freeing up valuable librarian time outside of the classroom.

We were relying on several pre-class activities, and needed the buy-in of the faculty to require them. In our pilot, we asked the faculty member to show the video created by North Carolina State University Libraries "Picking Your Topic is Research" and to have a short discussion about it with their students during class time. Then, as homework, students were to complete an online topic-development tutorial along with a printed worksheet. (For the pilot, we used the University of Minnesota Libraries "Strategies for Choosing a Topic" module.)

Students were also to watch a video created at DePaul on how to conduct a basic search in one of our databases and to locate two articles on their topic. Students were to bring the topic development worksheets and their articles to the in-person session. Faculty were strongly encouraged to give students a grade for completing these assignments.

The in-person library instruction emphasized metacognitive concepts through active learning exercises and de-emphasized task-oriented processes, since these are more easily offloaded onto tutorials and are always influx. Most of the class time was to be devoted to evaluating information and hands-on searching.

We taught seven sessions with four different teaching faculty, and four different librarians who were FYIWG members. Dur- ing the pilot, each session had a librarian instructor and a librarian as observer to fully document the session, recording details about what worked during instruction and what did not. We met with the participating faculty before the session and reached out to them after the session for feedback. While the overall curriculum addressed our learning objectives, the feedback led to simplifications of the pre-class activities for the following quarter. We removed the in-class video on picking a topic, since it presented much of the same information as the choosing a topic tutorial, and we asked students to only bring one article to class instead of two.

\section{Revising (spring and summer 2015)}

In spring quarter, we tested the curriculum again. Three librarians taught six sessions with four different faculty members. Our revised curriculum was stable at this point, but we did receive additional librarian and faculty feedback and made some adjustments. We created and revised handouts, including a research plan handout that could be used for student notetaking during the class and an evaluating sources worksheet. We also created an online "Research 101" guide that could be used during the session or as a review tool later. ${ }^{2}$ And, we created our own "developing a research question" tutorial. ${ }^{3}$

\section{Official launch (fall 2015)}

In fall 2015, we officially launched the new curriculum. At DePaul, autumn quarter has the fewest number of WRD 104 sections, generally tallying around 25 , and winter quarter is our busiest with at least 55 sections. Launching during autumn quarter gave librarians an opportunity to try out the new curriculum, and faculty had a chance to get familiar with it either through firsthand experience or our various communications if they were not teaching during autumn quarter.

\footnotetext{
(continues on page 82)
} 
prevent us from digitizing at all with those funds. Hopefully, greater understanding within the library community of the challenges of open licenses as outlined above, and the developing disciplinary standards for more accurate descriptive rights statements will also help funders adjust their standards accordingly.

\section{Notes}

1. Burrow-Giles Lithographic Co. v. Sarony, 111 U.S. 53 (1884); Bridgeman Art Library v. Corel Corp., 36 F. Supp. 2d 191 (S.D.N.Y. 1999); Meshwerks v. Toyota, 528 F.3d 1258 (10th Cir. 2008).

2. See Creative Commons, "CC0," https:// creativecommons.org/choose/zero/. n

("Successfully collaborating to revamp first-year instruction," continues from page 72)

At the end of summer, FYIWG held a workshop for librarians on the new curriculum. We ran through a sample lesson plan, explored various options for teaching concepts, and provided librarians with worksheets for the students. For faculty, we introduced the new curriculum at the annual First-Year Writing faculty meeting, included a written summary for their faculty handbook, and created a page on our website with information about the program. All WRD 104 faculty also received an email with information about the new program, and we offered to have a librarian follow up with them individually.

At the end of autumn quarter, we asked all of the librarians who taught sessions to provide feedback. We discussed experiences and observations during a December workshop. Based on this discussion, FYIWG created a second version of our evaluating articles worksheet, so that librarians had options for use in the classroom.

Faculty were also invited to provide comments via a brief survey. One faculty member suggested we create a web page for students that included all of the preclass assignments. Faculty could then just point their students to the web page-a simple enough solution, but one that we had not considered initially. So for winter quarter, we created that web page. ${ }^{4}$

\section{One year later}

We have now completed a full academic year with the new curriculum. Faculty are familiar with the curriculum and know what to expect. Librarians feel more comfortable teaching the higher-level thinking skills now that they have had experience. Our plans for the future include assessing the effectiveness of the curriculum so that we can continue to make informed decisions and periodically review the program. We also hope to develop a culture of sharing and observing among librarians when it comes to instruction. Now that we have established regular communication check-in points with the First-Year Writing program, we plan to continue to nurture that conversation so that our instruction program continues to be responsive.

\section{Notes}

1. Char Booth, Reflective Teaching, Effective Learning: Instructional Literacy for Library Educators (Chicago: ALA, 2011). USER is a simplified version of the ADDIE method (Analysis, Design, Development, Implementation, and Evaluation) of instructional design. USER stands for Understand, Structure, Engage, and Reflect.

2. Visit http://libguides.depaul.edu /research101.

3. Visit http://tutorials.library.depaul. edu/e-learning/developing-a-research -question/.

4. See http://library.depaul.edu/services/library-instruction/Pages/WRD-104 -and-HON-100-for-Students.aspx. 亿 